\title{
A Visão Cultural e Política de JOSUÉ de CASTRo e MARIO VARGAS LLOSA SOBRE A AMÉRICA LATINA SUBDESENVOLVIDA
}

\author{
Thiago Azevedo Sá de Oliveira
}

Submetido em 30 de maio de 2018.

Aceito para publicação em 11 de novembro de 2018.

Cadernos do IL, Porto Alegre, n. ${ }^{\circ}$ 57, novembro. p. 39-50

\section{POLÍTICA DE DIREITO AUTORAL}

Autores que publicam nesta revista concordam com os seguintes termos:

(a) Os autores mantêm os direitos autorais e concedem à revista o direito de primeira publicação, com o trabalho simultaneamente licenciado sob a Creative Commons Attribution License, permitindo o compartilhamento do trabalho com reconhecimento da autoria do trabalho e publicação inicial nesta revista.

(b) Os autores têm autorização para assumir contratos adicionais separadamente, para distribuição não exclusiva da versão do trabalho publicada nesta revista (ex.: publicar em repositório institucional ou como capítulo de livro), com reconhecimento de autoria e publicação inicial nesta revista.

(c) Os autores têm permissão e são estimulados a publicar e distribuir seu trabalho online (ex.: em repositórios institucionais ou na sua página pessoal) a qualquer ponto antes ou durante o processo editorial, já que isso pode gerar alterações produtivas, bem como aumentar o impacto e a citação do trabalho publicado.

(d) Os autores estão conscientes de que a revista não se responsabiliza pela solicitação ou pelo pagamento de direitos autorais referentes às imagens incorporadas ao artigo. A obtenção de autorização para a publicação de imagens, de autoria do próprio autor do artigo ou de terceiros, é de responsabilidade do autor. Por esta razão, para todos os artigos que contenham imagens, o autor deve ter uma autorização do uso da imagem, sem qualquer ônus financeiro para os Cadernos do IL.

\section{POLÍTICA DE ACESSO LIVRE}

Esta revista oferece acesso livre imediato ao seu conteúdo, seguindo o princípio de que disponibilizar gratuitamente o conhecimento científico ao público proporciona sua democratização.

http://seer.ufrgs.br/cadernosdoil/index

Quinta-feira, 22 de novembro de 2018. 


\title{
A VISÃO CULTURAL E POLÍTICA DE JOSUÉ DE CASTRO E MARIO VARGAS LLOSA SOBRE A AMÉRICA LATINA SUBDESENVOLVIDA ${ }^{3}$
}

\author{
THE CULTURAL AND POLITICAL VISION OF JOSUÉ \\ DE CASTRO AND MARIO VARGAS LLOSA ON LATIN \\ AMERICA UNDERDEVELOPED
}

Thiago Azevedo Sá de Oliveira*

\begin{abstract}
RESUMO: Propõe-se, neste artigo, interpretar o fluxo socialmente difuso das construções literárias de Josué de Castro, ressaltando do acervo josueniano, publicado no período de 1920 a 1960, o trânsito ético-estético expresso por esta produção - composta por ensaios, pelos contos do Documentário do Nordeste (1937) e pelo romance Homens e caranguejos (1967). Neste sentido, em face da conferência "Dentro y fuera de América Latina" (2005), presente no volume Sables y utopias: visiones de América Latina (LLOSA, 2009), aproxima-se a obra do escritor brasileiro à do peruano Vargas Llosa, comparando-as de forma ensaística, em busca de (re)discutir no âmbito da crítica literária a formulação de imagens possíveis para se pensar a geopolítica latino-americana, identitariamente marcada pela segregação cultural e econômica, bem como pela consciência de atraso (CANDIDO, 1989).
\end{abstract}

PALAVRAS-CHAVE: América Latina; subdesenvolvimento; Josué de Castro; Mario Vargas Llosa.

ABSTRACT: It is proposed in this article to interpret the socially diffuse flow of the literary constructions of Josué de Castro, highlighting from the josuenian collection, published in the period from 1920 to 1960, the ethico-aesthetic transit expressed by this production, namely composed by essays, by short stories the Documentário do Nordeste (1937) and the novel Homens e caranguejos (1967). In this sense, in view of the conference "Dentro y fuera de América Latina" (2005), present in the volume Sables y Utopias: visiones de América Latina (LLOSA, 2009), the brazilian writer's work is approached by the peruvian Vargas Llosa, comparing in an essay form, in order to (re) discuss in the scope of literary criticism the formulation of possible images to think about Latin American geopolitics, identified by cultural and economic segregation, as well as the consciousness of backwardness (CANDIDO, 1989).

KEYWORDS: Latin America; underdevelopment; Josué de Castro; Mario Vargas Llosa.

\section{Das premissas}

O que tem fome e te rouba o último pedaço de pão, chama-o teu inimigo mas não saltas ao pescoço do teu ladrão que nunca teve fome.

(Bertolt Brecht)

Se para Einstein a verdade soa como poesia da ciência, isto é, como ato de

\footnotetext{
${ }^{3}$ Este artigo abrange, preliminarmente, discussão a ser contemplada por meio de Tese em andamento acerca da leitura da obra literária de Josué de Castro, desenvolvida na Universidade Federal do Pará, sob a orientação do Prof. Dr. Sílvio Augusto de Oliveira Holanda.

* Mestre em Letras (Estudos Literários) pelo Programa de Pós-Graduação em Letras da Universidade Federal do Pará (PPGL/UFPA). Bolsista da Coordenação de Aperfeiçoamento de Pessoal de Nível Superior (CAPES). E-mail: prof.thiagoazevedo@gmail.com.
} 
cognição e de criatividade, o exercício da literatura - que, por assimetria, desenha mais que registra o sentido humano e cultural, "fornecendo uma nova imagem do mundo" (CASTRO, 1959b, p. 238) - provoca no escritor, médico e político brasileiro Josué de Castro (1908-1973) e no também escritor, jornalista e político peruano Mário Vargas Llosa (1936) o desejo de pensar a criação literária a contrapelo da produção cultural brasileira e latino-americana.

A fim de elucidar a semelhante operação intelectual dos textos de Josué de Castro e de Vargas Llosa, retoma-se, mesmo que por linhas gerais, o papel exercido pelos escritores brasileiros da Primeira República (1889-1930), possuindo como preâmbulo a obra-expoente Os Sertões, de Euclides da Cunha. Acerca deste período, o livro A literatura como missão (1987), de Nicolau Sevcenko, situa o mérito dos mosqueteiros intelectuais, antecipando, via de regra, a praxis do exercício intelectual como atitude política.

A prática intelectual esboçada por Euclides da Cunha, na tentativa de tencionar a narrativa como painel real da vida brasileira, sugere que as questões sociais sempre estiveram latentes no palimpsesto literário. Em contexto crítico e de formulação literária diverso, é pertinente acompanhar a textualidade ensaística concebida pelos intelectuais Josué de Castro e Vargas Llosa por meio de leitura que recupera a historicidade do pensamento euclidiano. Dessa forma, apresentá-los apenas como "Escritores-cidadãos" (SEVCENKO, 1987, p. 78) será insuficiente às pretensões deste artigo.

A contribuição contemporânea da conferência "Dentro y fuera de América Latina" (2005) de Mário Vargas Llosa à obra de Josué de Castro está amparada pelos conceitos da transculturação narrativa ${ }^{4}$ (ORTÍZ, 1978; RAMA, 1982) e da superação do real na antropologia literária do fictício e o imaginário (ISER, 2013). Há no diálogo entre Josué de Castro e Vargas Llosa o interesse de problematizar a literatura josueniana como expressão cultural ético-estética em meio ao debate sobre a imagem subdesenvolvida e fragmentada da América Latina.

O discurso em ação nos textos dos escritores brasileiro e peruano, uma vez cruzado pelos sentidos da antropologia, da ciência, da literatura e da sociologia, metodologicamente interfere na abordagem deste artigo, que parte do pressuposto de substituir o par "realidade/ficção" pela tríade "real-fictício-imaginário". Com vistas à mudança paradigmática da antropologia literária (ISER, 2013), aliada à sociocrítica (BERGUEZ et al., 1997), busca-se significar o subdesenvolvimento como elemento interno do texto, do "espaço onde se desenvolve e se efetua uma certa socialidade" (BERGUEZ et al., 1997, p. 144).

\section{Para além do intelectual da fome, o escritor}

"Josué de Castro era trezentos, trezentos e cinquenta em um homem só" (MELO, 2012, p. 112). A frase-epigrafe é de Mário de Andrade e condiz com a pluralidade de saberes do Josué de Castro - contista, ensaísta, geógrafo, médico, romancista e político. Em razão do recorte analítico, aqui se opta por realçar a figura do literato em detrimento do renomado estudioso da fome. Pela máscara do escritor, Josué de Castro ergue, a partir da prosa de ficção, uma textualidade sensível à debilidade

\footnotetext{
${ }^{4}$ Para Malinowski (apud ORTÍZ 1978, p. 5), a transculturação abrange o "proceso en el cual ambas partes de la ecuación resultan modificadas. Un proceso en el cual emerge una nueva realidad, compuesta y compleja; una realidad que no es una aglomeración mecánica de caracteres, ni siquiera un mosaico, sino un fenómeno nuevo, original e independiente".
} 
social e econômica brasileira, em escritos que depõem sobre a cosmovisão ${ }^{5}$ do autor acerca do mundo subdesenvolvido.

A carreira literária de Josué de Castro (1908-1973) tem início no ano de 1925, com a publicação "A doutrina de Freud e a Literatura Moderna" (1925), na Revista de Pernambuco. Entre as décadas de 1920 e 1940, o autor escreve sete poemas, oito contos, a cartilha poética A festa das Letras (1937), assinada em coautoria com Cecília Meireles, além de quarenta ensaios e crônicas que versam sobre cinema, literatura, teatro e pintura. À exceção da parceria com Cecília Meireles, reproduzida em livro pela editora Globo, de Porto Alegre, todo o conteúdo inicial foi disponibilizado à margem do consumo livresco, por meio de publicações em jornais e revistas de Recife, Rio de Janeiro e São Paulo.

A primeira fase do escritor Josué de Castro notabiliza o predomínio do "homem como meio e fim da evolução - com tudo aquilo que o procede para elevar as condições materiais (luta ao subdesenvolvimento e à fome) e morais (reestruturação cultural e cooperação entre os povos)" (DI TARANTO, 1993, p. 73). Por força do recorte analítico, será de suma importância optar pela síntese interpretativa dos textos primários desse autor, publicados de 1925 a 1946.

Sobre o ciclo produtivo que segue de 1946 a 1973, ano da morte de Josué de Castro, convém mencionar o período de consolidação intelectual do referido escritor e acadêmico. Com a publicação de Geografia da fome (1946), o autor torna-se mundialmente conhecido por dar à fome o estatuto científico, sociocultural e ontológico. Nesta fase, além do notório prestígio confirmado pela boa receptividade do livro Geopolítica da fome (1951), ocorre o lançamento do único romance josueniano, Homens e caranguejos, escrito originalmente em francês, no exílio político em Paris, no ano de $1966^{6}$.

O período introdutório do jovem escritor, recém-formado em Medicina na Bahia, sinaliza para o momento de afirmação da própria cultura brasileira, à época aquecida pela atmosfera de "afirmação categórica de independência política e econômica de nação. (...) Política que se pressente para os próximos dias como uma benéfica e irremovível contingência do impulso criador da nossa cultura" (CASTRO, 1959a, p. 129).

Nos primeiros anos da era política liderada por Getúlio Vargas, as aspirações alimentadas pelos grupos regionalista e modernista expõem o rebuliço do país e a pluralidade de tendências assimiladas pelo escritor pernambucano. Utilizando o folhetim como suporte, o então ensaísta e poeta defende a estética modernista, pondo-a em ação nos versos livres do poema Namoro (1928), publicado na Revista Antropofágica (São Paulo). Em 1936, no ensaio O romance do Nordeste ${ }^{7}$, Josué de Castro, com base no critério modernista de liberdade da escrita, rejeita o compromisso ideológico do poeta;

Não vejo necessidade para o poeta, de andar metrificando sua ideologia, nem

\footnotetext{
5 Aliada à compreensão da língua e da estruturação literária, o processo de transculturação narrativa, idealizado por Ángel Rama, considera a cosmovisão como "un tercer nivel de las operaciones transculturadoras, que es el central y focal representado por la cosmovisión que a su vez engendra los significados. Las respuestas de estos herederos 'plásticos' del regionalismo, depararon aquí los mejores resultados" (RAMA, 2007, p. 56, grifo no original).

${ }^{6}$ Em meio à cassação dos direitos políticos imputada pelo governo militar, o autor publica na capital francesa Des hommes et des crabes, traduzido para o português no ano seguinte à edição estrangeira. $\mathrm{O}$ volume brasileiro, com a tradução de Christiane Privat, possui circulação escassa até a abertura política.

${ }^{7}$ Vale somar a esta referência sua localização no livro Documentário do Nordeste (1937), feito o alerta para a alteração no título do texto: de "romance do Nordeste" para "O Nordeste e o romance brasileiro".
} 
para o romancista, de jogar nas suas histórias os argumentos filosóficos de suas atitudes políticas. Sou contra os romances de tese. $\mathrm{O}$ artista verdadeiro não é obrigado a ser conscientemente um libelista, porta-voz dos sentimentos recalcados de angústia e de revolta dos oprimidos de uma determinada situação histórico-social. Exigir isto dele seria acabar com a arte como expressão de espontaneidade. Seria tirar exatamente o caráter de originalidade que o individual revela em suas criações. $\mathrm{O}$ artista deve sentir o mundo livremente, sem compromissos diretos com quaisquer princípios filosóficos (CASTRO, 1936, s/n).

Pode-se entender o comentário josueniano como parte de uma crítica-rizoma, uma vez que o autor almeja intermediar o debate entre esteticistas e adeptos do sociologismo literário, isto é, Castro assimila a arte como espaço de originalidade cultural, de radicalização da experiência cotidiana. É possível verificar na incorporação da base modernista - ou vanguardista ${ }^{8}$, para usar a assimilação do termo dado pelos latino-americanos - a procura que visa a repensar as formas europeias vigentes na tradição estilística. Por isso, não parece incoerente deduzir, da oposição feita ao romance de tese, o afastamento do literato-Josué da realização artística por mero artifício de reprodução, ou de puro intelectualismo.

Para Josué de Castro, o puro intelectualismo já nascia morto e embalsamado, como "artifício que constitui uma grande massa do que se imprime por aí afora, páginas com frases arrebicadas e enfeitadas de adjetivos deslumbrantes. Literatura de efeitos artificiais, tendo para as pessoas de pensamento o significado dum zumbido confuso de insetos impertinentes" (CASTRO, 1936, s/n). Assim, verifica-se o depoimento do intelectual que, em rejeitando atributos acadêmicos, deseja exercer a literatura como atividade que cria realidade própria para dizer sobre o mundo, criando sua realidade.

Carvalheira (2002, p. 62) reconhece a proximidade de Josué de Castro com atores de grande destaque no século XX, caso de "Guimarães Rosa, Câmara Cascudo, Charles Chaplin, Sartre, Bertrand Russell, Getúlio Vargas, Rosselini, Abade Pierre, Darcy Ribeiro, Luiz C. Prestes, JK, José A. de Almeida, Anísio Teixeira, Alceu A. Lima e Barbosa L. Sobrinho". É, portanto, enfático pontuar a presença de figuras importantes que contribuem para a formação deste escritor, em especial no que tange ao apelo feito pela obra josueniana ao tema da condição humana.

Consciente de que a arte lida com a reação humana diante do conjunto de elementos circundantes, Josué de Castro abalizou a hipótese de não haver uma "literatura neutra, sem tendências, enquistada no absoluto dos cânones da arte" (CASTRO, 1936, s/n). Não obstante, o escritor brasileiro antecipou-se ao conceito da transculturação narrativa ${ }^{9}$, projetado por Ángel Rama na década de 1980, visto que, desde os anos de 1930, defendia a concepção da cultura como diretriz da obra literária, ou, especificamente, como tendência a ser seguida no curso do processo significativo da obra de arte:

Não pode haver vida social sem tendências. O estilo político, moral e estético é resultado do esforço do humano num determinado sentido a que o impulso

\footnotetext{
8 "El vanguardismo puso en entredicho el discurso lógico-racional que venía manejando la literatura a consecuencia de sus orígenes burgueses en el XIX. Tres tendencias literarias lo utilizaban, ya sea por la via de un lenguaje denotativo referencial, ya sea por la de los mecánicos diseños simbólicos: la novela regional, la novela social y la realista crítica" (RAMA, 2007, p. 57).

9 "Restablecer las obras literarias dentro de las operaciones culturales que cumplen las sociedades americanas, reconociendo sus audaces construciones significativas y el ingente esfuerzo por manejar auténticamente lós lenguajes simbólicos desarrollados por lós hombres americanos, es um modo de reforzar estos vertebrales conceptos de independencia, originalidad, representatividad. Las obras literarias no están fuera de las culturas sino que las coronan” (RAMA, 2007, p. 24).
} 
cultural o levou. No momento em que este estilo se gasta e perde sua significação, está morto e logo recomeça a criação de um outro, porque a humanidade só pode viver dentro de algum estilo que lhe dê forma orgânica. Assim nascem e morrem os vários ciclos culturais. Dentro desse imperativo de sinceridade a que o artista é compelido, ele será sempre tendencioso, porque o seu mundo interior não poderá ser nunca uma paisagem inanimada; será sempre uma paisagem humana, em marcha, em contínua transformação, a cada momento tendendo a alguma coisa, eternamente vindo a ser... (CASTRO, 1936, s/n).

A hipótese de que a cultura atua como elo entre a vida e a arte transparece no modus operandi da criação literária josueniana. A obra de Josué de Castro contempla a produção ético-estética dos anos de 1930. Logo, ao lado dos chamados escritores do Nordeste, Castro revela, por meio do fazer literário, imagens do mundo de fome, de pobreza extrema. Embora sua obra literária não tenha obtido êxito comparável ao de $O$ Quinze, por exemplo, Josué de Castro transita no circuito dos grandes escritores, sobretudo em função das relevantes pesquisas que fomentou a respeito da fome e dos efeitos do subdesenvolvimento.

A ligação de Josué de Castro com a arte está evidenciada pela rede de amizades do autor. Mário de Andrade (com quem se correspondeu por longos anos), Cecília Meireles (com quem escreveu A Festa das Letras), Rachel de Queiroz (a quem dedicou o livro Geografia da Fome), Lula Cardoso Aires (que ilustrou a primeira versão do mesmo Geografia da Fome), Cândido Portinari (que fez a ilustração de Josué de Castro, presente na obra $O$ Drama Universal da Fome), Jorge Amado, João Cabral de Melo Neto e Cícero Dias são alguns dos célebres artistas que gozaram da companhia do escritor pernambucano (MELO, 2012).

Deve-se acrescer ao grupo anterior o nome de Rodolfo Teófilo. Embora lembrado por Josué de Castro a título de sociólogo, Rodolfo Teófilo, nascido na Bahia e radicado no Ceará, é autor do romance naturalista $A$ fome (1890), narrativa cujo argumento consiste na trajetória dos retirantes da seca cearense em direção à capital, Fortaleza. Não se vislumbra despretensiosa a menção deste escritor ao lado de Rachel de Queiroz, cujos nomes constam nos agradecimentos do Geografia da fome.

No livro A Educação pela noite e outros ensaios (1989), Antonio Candido traça o panorama da consciência do subdesenvolvimento na literatura, em boa medida justificando o apontamento das distorções sociais originárias do processo da colonização latino-americana. Para o crítico, a assimilação do desalento é posterior à Segunda Guerra Mundial, sendo um sentimento difundido claramente a partir dos anos de 1950. "Mas desde o decênio de 1930 tinha havido mudança de orientação, sobretudo na ficção regionalista, que pode ser tomada como termômetro, dadas a sua generalidade e persistência" (CANDIDO, 1989, p. 142).

É talvez a ficção regionalista o ambiente estético mais receptivo às aspirações dos primeiros textos de Josué de Castro. O abandono da amenidade despertada no questionamento da fome e do subdesenvolvimento, "pressentindo ou percebendo o que havia de mascaramento no encanto pitoresco, ou no cavalheirismo ornamental, com que antes se abordava o homem rústico" (CANDIDO, 1989, p. 142), predomina na obra josueniana como traço crítico e narrativo.

A matriz artística ideologicamente gestada no ano de 1926, no Recife, concentra as atenções teóricas organizadas por Gilberto Freyre no Manifesto Regionalista, publicado em 1952. A série de prosas com características que destacam o homem e o espaço do Nordeste brasileiro tem origem no romance $O$ Cabeleira (1876), de Franklin Távora. Desde então, diversos autores buscam incorporar a suas obras uma "dimensão em que a literatura e artes visuais, política e urbanística, arte culinária e magia, música e 
artesanato, se tornam, todos, singular e coletivamente, ramo de ação social e instrumento de interpretação sociológica" (STEGAGNO-PICCHIO, 2004, p. 524).

Não por acaso, nos anos de 1928 e de 1930, Josué de Castro escreveu sete textos $^{10}$ no A província (Recife) ${ }^{11}$, jornal editado por Gilberto Freyre. Entre esses, o ensaio A elite brasileira, de 18 de maio de 1930, no qual o jovem escritor tece crítica à "inanição" dos intelectuais brasileiros, dividindo-os em dois grupos: "o pessimista desalentado que não crê no nacional" e para quem não vale a pena realizar nada; e o "patriota oficial, homem de ação nas palavras, de olhos entusiastas" (MELO, 2012, p. 121).

\section{Traços de cosmovisão e de contemporaneidade: Josué de Castro e Vargas Llosa}

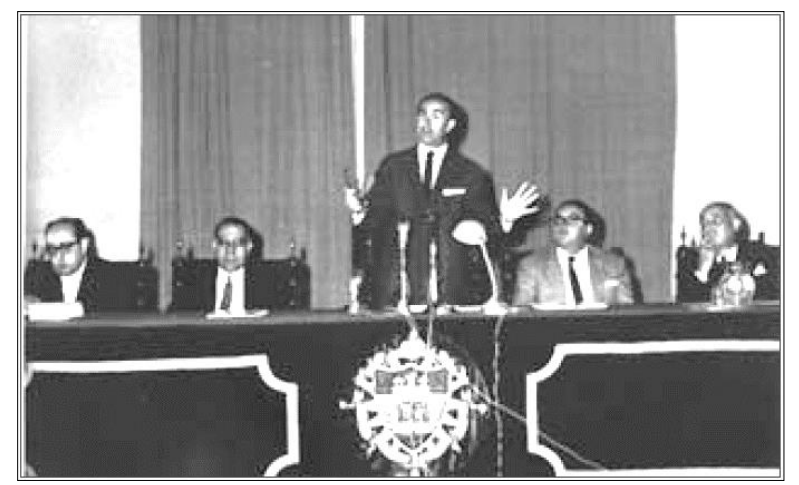

Figura 1 - Josué de

Castro e Mario

Vargas Llosa no debate Oú en est la révolution en Amérique Latine?, em julho de 1965, na

Espanha.

Fonte: MELO; NEVES, 2007, p. 251.

Para além da representação anímica assumida pela prosa de ficção oitocentista responsável pela consolidação do romance como gênero burguês, situa-se como característica da primeira fase da obra josueniana o diálogo da produção literária nacional com escritores e contextos culturais voltados à produção da América Latina. $\mathrm{O}$ autor busca aproximar a literatura brasileira dos vizinhos latino-americanos, indagando sobre os fatores responsáveis pela histórica hegemonia europeia (CASTRO, 1936, s/n). A propósito da expressão artística latino-americana,

Merece destaque o artigo Estudos Americanos - Salvador Diaz Miron ou o Espírito Mexicano (Homenagem ao General Medina Barron), publicado em 1 de agosto de 1929, no Diário da Manhã, do Recife. A pouco mais de um ano desta publicação havia falecido o poeta mexicano Salvador Diaz Miron, para Josué de Castro, um representante do "espírito mexicano". Sobre ele, diz: "Com a coragem de quem não ama a vida, e sim o seu ideal, ele incita a revolta contra o jugo do inclemente". Diaz Miron foi precursor da revolução no México e um iniciador do socialismo moderno, e como vários precursores

\footnotetext{
10 Pensamentos da Brodway (1928), A Revolução Mexicana vista de perto I (1930), A Revolução Mexicana vista de perto II (1930), O Orador Público (1930), Motivos Mexicanos (1930), A Elite Brasileira (1930) e Ensaio sobre o Leite (1930).

${ }^{11}$ Josué de Castro integra o grupo "dos artistas unidos em torno de Gilberto Freyre e do jornal por ele dirigido, a Província de Recife, [grupo composto por] personagens como José Lins do Rego, Olívio Montenegro, Aníbal Fernandes e Sílvio Rabelo. Todos em polêmica sociopolítica com o 'mestre', como aqueles que teriam escolhido estradas não coincidentes com a trilhada por ele; ou aqueles simplesmente atraídos ao círculo de seu fascinante programa de revalorização dos valores tradicionais, como Jorge de Lima e Manuel Bandeira” (STEGAGNO-PICCHIO, 2004, p. 524-525, grifo no original).
} 
e revoltados, expiou "o perigoso privillegio de viverem no futuro". A admiração que manifesta por estes tipos parece ter se materializado na sua caminhada. Josué chama atenção para o profundo desconhecimento dos latinos acerca da história e dos valores artístico-culturais da América Latina. Da Europa, conhecem o movimento modernista francês; mas do Brasil, ignoram Murilo Mendes, ou que Aluísio de Azevedo "é admiradíssimo na Inglaterra, e que o poeta mexicano Amado Nervo, é lido e conhecido em toda Europa". Da mesma forma, o México é um país desconhecido dos outros países americanos. Com esta afirmação, ele retoma a questão da integração latina e da valorização deste continente, presente no já referido artigo México-Brasil (MELO, 2012, p. 145).

A partir do ensaio Estudos Americanos - Salvador Diaz Miron ou o Espírito Mexicano (Homenagem ao General Medina Barron), Josué de Castro provoca a discussão em torno da "inexistência de intercambio intelectual e communicações directas com Sulamerica" (CASTRO, 1929, s/n). Nesse sentido, desde fins da década de 1920, o discurso favorável à integração artística e literária da América Latina aponta caminhos viáveis para questionamentos semelhantes, suscitados em 2005 por Mario Vargas Llosa durante conferência em Berlim.

Sendo sua obra aclamada pela crítica literária, apesar das ressalvas que lhe são feitas ao espírito conservador de seu pensamento político, Vargas Llosa é tido como um dos responsáveis pelo boom da literatura latino-americana na década de 1960, ao lado de Julio Cortázar, Carlos Fuentes e Gabriel García Márquez. Autor dos romances La ciudad y los perros (A cidade e os cachorros) (1963), La guerra del fin del mundo (A guerra do fim do mundo) (1981) e do mais recente El héroe discreto (O herói discreto) (2013), o escritor peruano tem o aval da crítica a sua ficção ${ }^{12}$ em premiações expressivas, a exemplo do Cervantes, em 1995 (o mais importante prêmio literário da língua espanhola) e do Nobel de Literatura, no ano de 2010.

A conferência "Dentro y fuera de América Latina", conduzida pelo escritor Mario Vargas Llosa durante evento de entrega do título de Doutor honoris causa pela Universidade de Humboldt, apresenta novos contornos críticos à discussão acerca da cultura, da identidade e da geopolítica latino-americanas. Amiúde, a questão "¿Qué significa sentirse um latinoamericano?" (LLOSA, 2009, p. 346) aproxima-se das reflexões introduzidas por Josué de Castro desde os anos de 1930.

O texto da conferência conduzida por Llosa, publicado em 2009 na edição argentina do livro Sables y utopias: visiones de América Latina, remete aos aspectos da comunidade cultural latino-americana formada por países até hoje pouco relacionados entre si. De um lado, tem-se o continente marcado "por sus astronómicas diferencias de ingreso entre pobres y ricos, sus niveles de marginación, desempleo y pobreza, por la corrupción que socava sus instituiciones" (LLOSA, 2009, p. 350), de outro, a América Latina é indicada na arte pela diversidade cultural da região em níveis de elaboração e originalidade.

Sólo en el campo de la cultura la integración latinoamericana ha llegado a ser algo real, impuesto por la experiencia y la necesidad - todos quienes escriben, componen, pintan y realizan cualquier otra tarea creativa descubren

\footnotetext{
${ }^{12}$ Assim como Josué de Castro, Vargas Llosa habilita-se à função de crítico-ensaísta a fím de reiterar o compromisso subjetivo da ficção para além da história e das descrições científicas da realidade. Para ele, "Una ficción lograda encarna la subjetividad de una época y por eso las novelas, aunque cotejadas con la historia, mientan, nos comunican unas verdades huidizas y evanescentes que escapan siempre a los descriptores científicos de la realidad. Sólo la literatura dispone de las técnicas y poderes para destilar ese delicado elixir de la vida: la verdad escondida en el corazón de las mentiras humanas" (LLOSA, 2003, p. 27).
} 
que lo que los une es mucho más importante que lo que los separa de los otros latinoamericanos -, en tanto que en los otros dominios, la política y la economía sobre todo, los intentos de unificar acciones gubernativas y mercados se han visto siempre frenados por los reflejos nacionalistas, por desgracia muy enraizados en todo el continente: es la razón por la que todos los organismos concebidos para unir a la región, desde el Pacto Andino hasta Mercosur, nunca han prosperado. (...) Aunque no suele abordarse de manera explícita, un asunto merodea por todos los vericuetos de la cultura latinoamericana: la abismal contradicción que existe entre su realidad social y política y su producción literaria y artística (LLOSA, 2009, p. 347-350).

Vargas Llosa traz para a contemporaneidade a preocupação de Josué de Castro no que se refere à integração latino-americana. Ainda que admitindo ter "descoberto" a América Latina fora dela, nos anos de 1960, uma vez que durante esse período Paris se transforma na capital da literatura latino-americana, o pensamento de Llosa corresponde ao chamado boom da literatura da América Latina. Embora exilados de suas pátrias, diversos escritores latinos, a exemplo de Llosa e García Márquez, produziram textos que corroboram a legitimidade da prosa do "novo mundo", mas sem perder de vista as bases da tradição europeia ${ }^{13}$.

Em tempo, o autor peruano afiança que a maioria dos escritores dessa "región del mundo (América Latina) había vivido, o vivía en París, o pasaba por esa ciudad, y los que no, terminaban siendo descubiertos, traducidos y promovidos por Francia" (LLOSA, 2009, p. 345). Em temporalidade semelhante, esse foi o contexto produtivo de Homens e caranguejos, único romance escrito por Josué de Castro.

No primeiro ano de exílio em Paris, a sensibilidade diversificada para a arte conduziu Josué de Castro a repensar, por meio da literatura, a infância passada no Recife. Homens e caranguejos é o arranjo estilístico de oitos contos, dentre eles "O ciclo do caranguejo" e "O despertar dos mocambos"14. Não obstante o conto ser um gênero literário identificado com a autonomia da história do país - como os contos machadianos no século XIX e os contos rosianos no século XX -, Stegagno-Picchio, (2004, p. 542) interpreta que o conto, "por um lado, nutre-se de um filão popular que lhe fornece a matriz simbólica, a intenção moralista ou a malícia do exemplum; e, por outro, uma imitação europeia, sobretudo francesa".

Traduzido em espanhol, inglês, português, alemão e italiano, o texto romanesco de Homens e caranguejos foi "adaptado para o teatro por Gabriele Cousin, com o título Le Cycle du Crabe ou Les Aventures de Zé Luis, Maria et Leurs fils João (Gallimard, 1969)" (LINHARES, 2007, p. 24). Deve-se frisar que o romance josueniano opera não apenas a intertextualidade de gêneros, mas também se apropria da cosmovisão, a fim de transculturar a paisagem humana dos mocambos ${ }^{15}$ do Recife e integrar a narrativa brasileira ao universo latino-americano de "humanidade e poesia, desumanidade e miséria" (RONDINI, 2012, p. 173).

"O Recife, a cidade dos rios, das pontes e das antigas residências palacianas é também a cidade dos mocambos, das choças, dos casebres de barro batido a sopapo,

\footnotetext{
13 “Además de leer a los escritores de mi proprio país, leía casi exclusivamente a escritores norte americanos e europeos, sobre todo franceses" (LLOSA, 2009, p. 345).

${ }^{14}$ In: CASTRO, Josué de. O ciclo do caranguejo. A Platéia, São Paulo, 30 mar. 1935. CASTRO, Josué de. O despertar dos mocambos. Diário Carioca, Rio de Janeiro, 16 fev. 1936. Os demais seis contos, "A cidade", "João Paulo", "Ilha do leite", "Assistência social", "Solidariedade humana" e "A seca", foram publicados no livro Documentário do Nordeste, de 1937.

15 "Tanto quanto a Paris dos bulevares e dos amantes é também a cidade daqueles que não têm para onde ir, o Recife de que nos fala Josué de Castro é a cidade que não quer ver os mocambos. Com a importante diferença de que no contexto de Homens e caranguejos os pobres já têm seu lugar de destino: os mocambos nos mangues" (RONDINI, 2012, p. 173).
} 
cobertas de capim, de palha de coqueiro e de folhas de Flandres" (CASTRO, 1967, p. 27)" é o fragmento extraído do primeiro parágrafo de Homens e caranguejos. Nele, a apropriação narrativa das diferenças da ocupação urbanística retoma a cosmovisão transcultural do mocambo. Ainda que por contraste, isto é, avessa à ideia de homogeneidade pela qual Gilberto Freyre pressupõe o "mucambo" como "um valor pelo que representa a harmonização estética: a construção humana harmonizada a natureza" (FREYRE, 1996, p. 50), Castro traz em sua obra a identificação do espaço como traço telúrico da ficcção.

O biombo do continente latino-americano mestiço, entretanto, em dissonância com a ideia da mestiçagem harmoniosa, expressa as diferenças do processo transculturador, realizado "[...] em três níveis diversos e complementares: o da língua, o da estruturação da narrativa e o da cosmovisão" (ABDALA JÚNIOR, 2004, p. 88). Aponta-se, em suma, a resposta conduzida no texto/conferência de Vargas Llosa (2009, pp. 346-347), isto é, a mestiçagem continua ocorrendo como ato de transculturação e terminará por prevalecer, "dando a América Latina el perfil distintivo de un continente mestizo (...) América Latina no puede renunciar a esa diversidad multicultural que hace de ella un prototipo del mundo".

\section{Considerações finais}

Em função de compreender que a crítica da obra literária não nega o aparecimento dos vestígios deixados em suspense no horizonte de recepção dos textos (JAUSS, 1994), assimila-se o perfil ético expresso a partir das obras de Castro e Vargas Llosa na interpretação comparativa de discursos que contemplam, a um só tempo, estratégias de criação literária e de realização ideológica. Não obstante, cabe frisar o caráter participativo destes autores na vida social de seus países. Neste sentido, a vida social e, em específico, a consciência com que ambos escritores narram as agruras causadas pelo subdesenvolvimento caracterizam a feição imbricada de texto e contexto. Desse modo, ressalta-se a presença de crítica que se nutre da base sociológica, considerando a biografia social como elemento importante para que o leitor entenda, através da ficção, o imaginário cultural e político da América Latina.

Nos anos de 1960, os regimes totalitaristas latino-americanos deram conotação política à cooperação Brasil-França, como no caso do golpe militar brasileiro de 1964 . Não por acaso, o contexto de exceção obrigou Josué de Castro, Jorge Amado, Vargas Lllosa, dentre outros artistas, escritores e intelectuais latinoamericanos, a se retirarem do continente. Em sendo a literatura uma elaboração de novos meios expressivos e um desenvolvimento de nova consciência artesanal, as questões provocadas pela especulação do subdesenvolvimento na obra literária josueniana evidenciam a relação da obra literária com a realidade na multiplicidade de aspectos textuais, extratextuais e intertextuais.

A forma fragmentada como estão dispostos os textos literários de Josué de Castro, em edições esgotadas ou cronologicamente distantes, reforça a necessidade de se aprofundar o parecer de juízos atribuídos à bibliografia deste autor, a fim de atualizar a circulação de sua obra. Assenta-se como justificativa relevante não apenas a simples difusão da literatura josueniana, ou do pensamento intelectual movido pelo autor, mas a atividade de integração da obra ficcional ao pensamento cultural e literário latinoamericano que discute a potencialidade criativa gerada pela consciência de atraso. Eis, por isso, o último pedaço de pão, como alimento narrativo de fazer ético e estético. 


\section{REFERÊNCIAS}

ABDALA JÚNIOR, Benjamin (Org.). Margens da cultura: mestiçagem, hibridismo e outras misturas. São Paulo: Boitempo, 2004.

BERGEZ, Daniel et. al. Métodos críticos para a análise literária. Trad. Olinda Maria Rodrigues Prata. São Paulo: Martins Fontes, 1997.

CANDIDO, Antonio. Literatura e subdesenvolvimento. In: noite e outros ensaios. São Paulo: Ática, 1989. p. 140-162.

A educação pela

CARVALHEIRA, Renato. Josué de Castro: o sociólogo da fome. 2002. Dissertação

(Mestrado em Sociologia) - Universidade de Brasília, Brasília, 2002.

CASTRO, Josué de. A doutrina de Freud e a Litteratura Moderna. Revista de

Pernambuco, Recife, 1925.

Estudos Americanos - Salvador Diaz Miron ou o Espírito Mexicano

(Homenagem ao General Medina Barron). Diário da Manhã, Recife, 1929.

. O regionalismo e a cultura brasileira. In:

Documentário do Nordeste.

2. ed. São Paulo: Brasiliense, 1959a. p. 125-130.

Ensaios de biologia social. 2. ed. São Paulo: Brasiliense, 1959b.

Homens e caranguejos. São Paulo: Brasiliense, 1967.

O romance do Nordeste. Diário Carioca, Rio de Janeiro, 15 de mar. 1936.

CASTRO, Josué de; MEIRELES, Cecília. A festa das Letras. 2. ed. Rio de Janeiro:

Nova Fronteira, 1996.

DI TARANTO, Giuseppe. O subdesenvolvimento da América Latina. In:

subdesenvolvimento na obra de Josué de Castro. Trad. Maria de Fátima Mendes

Leal. Belém: CEJUP, 1993.

FREYRE, Gilberto. Manifesto regionalista. 7. ed. Recife: FUNDAJ, Ed. Massangana, 1996.

ISER, Wolfgang. O fictício e o imaginário: perspectivas de uma antropologia literária. Trad. Johannes Kreschmer. 2. ed. Rio de Janeiro: EdUERJ, 2013.

JAUSS, Hans Robert. A história da literatura como desafio à teoria literária. Trad. Sérgio Tellaroli. São Paulo: Ática, 1994.

LINHARES, Maria Yedda Leite. Biografia. In: FERNANDES, Bernardo Mançano; GOLÇALVES, Carlos Walter Porto (Orgs.). Josué de Castro - vida e obra. 2 ed. Expressão Popular: São Paulo, 2007.

LLOSA, Mario. Dentro y fuera de América Latina. In: . Sables y utopias: visiones de América Latina. Seleção e prólogo de Carlos Granés. Buenos Aires: Aguilar, 2009. p. 345-358.

La verdad de las mentiras. Madrid: Santillana, 2003.

MELO, Normando Jorge de Albuquerque. Josué de Castro: um compromisso ético, estético e pedagógico. In: SILVA, Tânia Elias Magno (Org.). Josué de Castro. Rio de Janeiro: Fundação Miguel de Cervantes, 2012. p. 108-149.

MELO, Marcelo Mario de; NEVES, Teresa Cristina Wanderley (Orgs.). Josué de Castro. Perfis parlamentares 52. Brasília: Câmara dos Deputados, 2007.

ORTÍZ, Fernando. Contrapuento cubano del tabaco y el azúcar. Caracas: Biblioteca Ayachucho, 1978.

RAMA, Ángel. Más allá del boom: literatura y mercado. Buenos Aires: Folios Ediciones, 1982

Transculturación narrativa en América Latina. Buenos Aires: Ediciones El Andariego, 2007.

RONDINI, Luiz Carlos. Homens e caranguejos: o diálogo entre arte, vida e ciência. In: 
SILVA, Tânia Elias Magno (Org.). Josué de Castro. Rio de Janeiro: Fundação Miguel de Cervantes, 2012. p. 163-187.

SEVCENKO, Nicolau. Literatura como missão: tensões sociais e criação cultural na Primeira República. São Paulo: Brasiliense, 1987.

STEGAGNO-PICCHIO, Luciana. História da literatura brasileira. Trad. Pérola de Carvalho e Alice Kyoko. 2. ed. Rio de Janeiro: Nova Aguilar, 2004. 